\title{
revista educação
}

DOI: $10.33947 / 1980-6469-v 14 n 1-3498$

\section{UM DIÁLOGO MATEMÁTICO ENTRE A BASE NACIONAL COMUM CURRICULAR E A PROPOSTA CURRICULAR DE GUARULHOS - QSN}

\section{A MATHEMATICAL DIALOGUE BETWEEN THE COMMON CURRICULAR NATIONAL BASE AND THE CURRICULAR PROPOSAL OF GUARULHOS - QSN \\ Vanessa Sena de Paula ${ }^{1}$ \\ RESUMO}

Este trabalho tem como objetivo comparar a nova proposta curricular aprovada pelo Governo Federal em 2017 denominada Base Nacional Comum Curricular e o Quadro de Saberes Necessários, atual proposta da rede de ensino do município de Guarulhos. Para tanto serão utilizadas como referências os próprios documentos supracitados as vistas de fortalecer e experienciar um movimento que será realizado pelas Secretarias de Educação Brasil a fora. A análise busca aproximações e distâncias entre os conteúdos matemáticos em Probabilidade e Estatística/Tratamento da Informação que ora podem dialogar e direcionar para uma mesma prática ora se distanciar ou negligenciar alguns conhecimentos.

PALAVRAS-CHAVE: Matemática. Currículo. Conhecimento Matemático. BNCC. QSN.

\section{ABSTRACT}

This paper aims to compare the new curricular proposal approved by the Federal Government in 2017 called the National Curricular Common Base and the Required Knowledge Framework, current proposal of the teaching system of the municipality of Guarulhos. To do so, the documents mentioned above will be used as references to strengthen and experience a movement that will be carried out by the Secretariats of Education in Brazil. The analysis seeks approximations and distances between the mathematical contents in Probability and Statistics / Information Processing that can now dialogue and direct to the same practice, or distance or neglect some knowledge.

KEYWORDS: Mathematics. Curriculum. Mathematical Knowledge. BNCC. QSN.

1 Especialista em Educação Matemática para os anos iniciais do Ensino Fundamental. 


\section{INTRODUÇÃO}

"O homem pode se tornar homem [...] somente através da educação. Ele não é nada mais do que aquilo que a educação dele o faz [...] e, por detrás da educação esconde-se o grande segredo da perfeição da natureza humana."

Emmanuel Kant

Neste artigo realiza-se um estudo comparativo cujo foco das discussões será a Base Nacional Comum Curricular - BNCC e a Proposta Curricular da Rede Municipal de Guarulhos: Quadro de Saberes Necessários e seus conteúdos matemáticos, mais especificamente os saberes relativos ao Tratamento da Informação.

Composta por 10 competências gerais, a BNCC, orienta que estas que devem ser asseguradas ao estudante ao longo da Educação Básica. Mais especificamente na segunda e quarta competência tratar-se-a das questões lógico-matemáticas conforme segue:

2. Exercitar a curiosidade intelectual e recorrer à abordagem própria das ciências, incluindo a investigação, a reflexão, a análise crítica, a imaginação e a criatividade, para investigar causas, elaborar e testar hipóteses, formular e resolver problemas e criar soluções (inclusive tecnológicas) com base nos conhecimentos das diferentes áreas.

4. Utilizar diferentes linguagens - verbal (oral ou visual-motora, como Libras, e escrita), corporal, visual, sonora e digital -, bem como conhecimentos das linguagens artísticas, matemática e científica, para se expressar e partilhar informações, experiências, ideias e sentimentos em diferentes contextos e produzir sentidos que levem ao entendimento mútuo. (BRASIL, 2017, p. 9).

No Quadro de Saberes Necessários - QSN contamos com 11 finalidades para o Ensino Fundamental nas quais duas predominantemente apontam para 0 trabalho com a Linguagem Matemática:

Utilizar as diferentes linguagens - verbais, matemática, gráfica, artística e corporal - como meio para expressar e comunicar suas ideias, entender, interpretar e usufruir das produções da cultura.

Questionar a realidade formulando problemas e tratando de resolvê-los, utilizando para isso o pensamento lógico, a criatividade, a intuição, a capacidade de análise crítica, selecionando procedimentos e verificando sua adequação (GUARULHOS, 2009, p. 55).

Nos texto introdutório da BNCC observa-se o fio condutor das discussões matemáticas um tanto parecidas. Nesse sentido, será que nessa breve comparação necessita-se reescrever parte tão importante do conteúdo a ser ensinado ou será surpreendente a descoberta de que uma está contida na outra?

\section{Comparação do conhecimento matemático}

Recentemente foi aprovada pelo Conselho Nacional de Educação a Base Nacional Curricular Comum com homologação realizada no dia 20 de dezembro de 2017. Com vistas a proporcionar aos estudantes brasileiros um rol de conteúdos "mínimos" a serem estudados. Os municípios e estados por meio de suas secretarias e departamentos pedagógicos farão parte de um movimento urgente de construir suas propostas curriculares para dialogar com a nova proposta nacional conforme orienta trecho a seguir extraído no site orientador do Ministério da Educação - MEC

A Base é uma referência obrigatória, mas não é o currículo. Seu papel será justamente o de orientar a revisão e a elaboração dos currículos nos estados e nos municípios. A Base estabelece os objetivos que se espera que os estudantes venham a atingir, enquanto o currículo define como alcançar esses objetivos. De maneira simples, é possível afirmar que a Base indica o destino aonde se quer chegar. O currículo traça o caminho (BRASIL, 2017, s.p.).

Para Vasconcellos (2009), há duas ideias principais que permeiam o conceito de currículo: um como proposta que seleciona e organiza conteúdos e outro 
como percurso efetivamente percorrido pelo sujeito e que não necessariamente está fixado em uma proposta. Ao analisar essas duas definições ficam evidentes a importância de cada grupo direcionar um olhar apurado para as propostas existentes, as relações diretas com os estudantes, as dimensões de tempo e espaço, suas localidades e unidades escolares.

Trabalhando há dez anos como professora em uma rede de ensino da grande São Paulo, mais especificamente no município de Guarulhos e há cinco como formadora de professoras neste mesmo local observo a necessidade de um trabalho científico voltado para esta relação entre o novo currículo nacional com aquele que vem a ser o meu guia/norteador de muitas discussões para o trabalho com a Matemática nos anos iniciais do Ensino Fundamental, a Proposta Curricular - Quadro de Saberes Necessários, uma construção coletiva e dialógica realizada em abril de 2010 com desenvolvimento e aprovação de docentes e comunidade escolar que participaram amplamente das discussões. Sua revisão e aprovação final passou pelo Departamento de Orientações Pedagógicas (DOEP) responsáveis pelo direcionamento e fechamento da proposta.

De acordo com o material norteador da Base $^{2}$ essa pode ser uma ação própria ou coletiva a medida que pode ser executada com parceiros de uma mesma região.

Para o presente trabalho focaremos na área de Matemática cujas propostas, cada qual a sua maneira, referem ao que seria um dos elementos marcantes de uma proposta na discussão do conhecimento matemático escolar.

No Quadro de Saberes Necessários (2009, p. 62):

Um currículo eficiente quanto aos saberes de matemática permite que o sujeito desenvolva habilidades de resolver problemas, lide com informações numéricas, faça inferências, possa agir de forma crítica e independente e perceba o uso social e o papel formativo dessa disciplina, ajudando-o a estruturar seu pensamento e raciocí-

\footnotetext{
${ }^{2}$ Assim como vem sendo conhecida comumente em suas veiculações nas mídias e também por educadores e toda comunidade escolar ao redor de todo o país.
}

nio lógico. Isso tudo Ihe possibilitará exercer, de forma mais plena, o exercício de sua cidadania.

Na Base (2017, p. 274):

Portanto, a BNCC orienta-se pelo pressuposto de que a aprendizagem em Matemática está intrinsecamente relacionada à compreensão, ou seja, à apreensão de significados dos objetos matemáticos, sem deixar de lado suas aplicações. Os significados desses objetos resultam das conexões que os alunos estabelecem entre eles e os demais componentes, entre eles e seu cotidiano e entre os diferentes temas matemáticos (BRASIL, 2017, p. 274).

Percebe-se nessa introdução que as concepções não divergem apesar de apontarem questões diferentes. Observa-se como pontos centrais na construção de um aprendizado com sentido e significado para o aluno considerando o cotidiano e a sua função social além das conexões com outras áreas do conhecimento.

Antes de direcionar o foco para a discussão principal acerca dos saberes matemáticos em si, é importante ressaltar que a proposta do município de Guarulhos tem como cerne a questão dos ciclos de formação visando com que o saber ${ }^{3}$ seja trabalhado ao longo da permanência do estudante nesta etapa escolar ficando a cargo de cada escola sua estruturação em seus planejamentos.

A Base traz uma perspectiva diferente dessa à medida que seus objetivos, denominados habilidades ${ }^{4}$ estão divididos anualmente na etapa referente aos primeiros anos do Ensino Fundamental. Ainda assim, é possível e necessário estabelecer uma relação entre o que está proposto nacionalmente e o que precisamos afinar a partir do que já realizamos.

Nesse momento em vistas de ser um estudo inicial será necessária uma observação geral e logo após um olhar mais atento para o bloco de saberes / bloco de habilidades Tratamento da Informação.

\footnotetext{
${ }^{3}$ Para Vasconcellos (2009) p. 160, um saber pode ser entendido como o que deve ser ensinado, o que é importante, relevante, o que vale a pena fazer parte do currículo, o que o educando deve estudar, aprender.

${ }^{4}$ A Base (2017) p. 9 aponta habilidades como capacidades práticas, cognitivas e sócioemocionais.
} 
A proposta curricular município de Guarulhos é dividida em quatro grandes temas: Números e Operações, Espaço e Forma, Grandezas e Medidas e Tratamento da Informação. Já na Base a subdivisão se deu em cinco unidades temáticas, sendo: Números, Álgebra, Geometria, Grandezas e Medidas e Probabilidade e Estatística.

Ao compararmos perceberemos algumas mudanças de nomenclatura, mas que ainda assim se falam em mesmos conceitos como: Números e Operações e Números / Espaço e Forma - Geometria etc.

A grande novidade fica por conta da inserção da unidade temática Álgebra que mesmo podendo em alguns momentos estar diluídas em outros saberes não se faz presente enquanto bloco de saberes.

Nesse momento aprofundam-se os olhares para um bloco de saberes/habilidades que com a mudança de nomenclatura gera novas ideias e possibilidades de trabalho que seria Probabilidade e Estatística - Tratamento da Informação. Esta escolha não se dá apenas pelo acaso ou pela curiosidade, mas sim por se tratar de uma temática com entrada recente em nossas propostas curriculares.

Antes da década de 80, a Estatística e assuntos correlatos, como probabilidade e a análise combinatória, eram propostos apenas para os anos finais do Ensino Fundamental e Ensino Médio. No entanto, devido a importância destes conceitos para o exercício da cidadania, e estudos da área da Psicologia que apontam a possibilidade de poderem ser trabalhados com crianças menores, indica-se a inserção da Educação Estatística já nos anos iniciais (BRASIL, 2014, p. 7).
Para elucidar essa discussão é importante constar aqui os saberes que posteriormente serão analisados / comparados. Na tabela abaixo se encontram os saberes elencados para Tratamentos da Informação a serem trabalhados ao longo dos cinco anos iniciais do Ensino Fundamental.

Tabela 1 - QSN e seus saberes necessários para o grande tema Tratamento da Informação

Saberes a serem introduzidos e aprofundados ao longo de todo o ciclo do Ensino Fundamental I

1. Elaborar e organizar tabelas e gráficos, utilizando coletas de dados em situações do cotidiano, bem como ler e interpretar suas informações.

2. Resolver situações-problema com dados apresentados de maneira organizada por meio de tabelas e gráficos.

3. Ler informações e dados apresentados de maneira organizada por meio de gráficos (particularmente em gráficos de colunas).

4. Utilizar a noção de probabilidade, combinatória e estatística em situações - problema.

A partir deste quadro aponta-se efetivamente a comparação entre os saberes acima listados e a nova organização proposta pela Base. Abaixo seguimos com os objetos de conhecimentos, as habilidades e os saberes relacionados às mesmas.

Tabela 2 - BNCC e seus objetos de conhecimento e habilidades para a unidade temática Probabilidade e Estatística e a relação com os saberes do Quadro de Saberes Necessários: 


\begin{tabular}{|c|c|c|}
\hline Objeto de conhecimento & Habilidades & Saberes \\
\hline \multicolumn{2}{|c|}{$1^{\circ}$ ano } & Para todos os anos \\
\hline Noção de acaso & $\begin{array}{l}\text { (EF01MA20) Classificar eventos } \\
\text { envolvendo o acaso, tais como } \\
\text { "acontecerá com certeza", } \\
\text { "talvez aconteça" e "é impossível } \\
\text { acontecer", em situações do } \\
\text { cotidiano. }\end{array}$ & $\begin{array}{l}\text { 4- Utilizar a noção de probabilidade, } \\
\text { combinatória e estatística em } \\
\text { situações - problema. }\end{array}$ \\
\hline $\begin{array}{l}\text { Leitura de tabelas e de gráficos de } \\
\text { colunas } \\
\text { Simples }\end{array}$ & $\begin{array}{l}\text { (EF01MA21) Ler dados expressos } \\
\text { em tabelas e em gráficos de colunas } \\
\text { simples. }\end{array}$ & $\begin{array}{l}\text { 3- Ler informações e dados } \\
\text { apresentados de maneira } \\
\text { organizada por meio de gráficos } \\
\text { (particularmente em gráficos de } \\
\text { colunas). }\end{array}$ \\
\hline \multicolumn{2}{|c|}{\begin{tabular}{lr|l}
$\begin{array}{l}\text { Coleta e organização de } \\
\text { informações }\end{array}$ & $\begin{array}{l}(\text { EF01MA22) Realizar pesquisa, } \\
\text { Registros pessoais } \\
\text { envelvendo até duas variáveis } \\
\text { categóricas de seu interesse e }\end{array}$ \\
comunicação de & paniverso de até 30 elementos, \\
informações coletadas & & $\begin{array}{l}\text { organizar dados por meio de } \\
\text { representações pessoais. }\end{array}$
\end{tabular}} & $\begin{array}{l}\text { 4- Utilizar a noção de probabilidade, } \\
\text { combinatória e estatística em } \\
\text { situações - problema. }\end{array}$ \\
\hline \multicolumn{3}{|c|}{$2^{\circ}$ ano } \\
\hline $\begin{array}{l}\text { Análise da ideia de aleatório em } \\
\text { situações do } \\
\text { Cotidiano }\end{array}$ & $\begin{array}{l}\text { (EF02MA21) Classificar resultados } \\
\text { de eventos cotidianos aleatórios } \\
\text { como "pouco prováveis", } \\
\text { "muito prováveis", "improváveis" e } \\
\text { "impossíveis". }\end{array}$ & $\begin{array}{l}\text { 4- Utilizar a noção de probabilidade, } \\
\text { combinatória e estatística em } \\
\text { situações - problema. }\end{array}$ \\
\hline $\begin{array}{l}\text { Coleta, classificação e e } \\
\text { representação de dados em tabelas } \\
\text { simples e de dupla entrada e em } \\
\text { gráficos de colunas }\end{array}$ & $\begin{array}{l}\text { (EF02MA22) Comparar informações } \\
\text { de pesquisas apresentadas por } \\
\text { meio de tabelas de dupla entrada e } \\
\text { em gráficos de colunas simples ou } \\
\text { barras, para melhor compreender } \\
\text { aspectos da realidade próxima. } \\
\text { (EF02MA23) Realizar pesquisa } \\
\text { em universo de até } 30 \text { elementos, } \\
\text { escolhendo até três variáveis } \\
\text { categóricas de seu interesse, } \\
\text { organizando os dados coletados em } \\
\text { listas, tabelas e gráficos de colunas } \\
\text { simples. }\end{array}$ & $\begin{array}{l}\text { 3- Ler informações e dados } \\
\text { apresentados de maneira } \\
\text { organizada por meio de gráficos } \\
\text { (particularmente em gráficos de } \\
\text { colunas). } \\
\text { 3- Ler informações e dados } \\
\text { apresentados de maneira } \\
\text { organizada por meio de gráficos } \\
\text { (particularmente em gráficos de } \\
\text { colunas). }\end{array}$ \\
\hline \multicolumn{3}{|c|}{$3^{\circ}$ ano } \\
\hline $\begin{array}{l}\text { Análise da ideia de acaso em } \\
\text { situações do } \\
\text { cotidiano: espaço amostral }\end{array}$ & $\begin{array}{l}\text { (EF03MA25) Identificar, em eventos } \\
\text { familiares aleatórios, todos os } \\
\text { resultados possíveis, estimando } \\
\text { os que têm maiores ou menores } \\
\text { chances de ocorrência. }\end{array}$ & $\begin{array}{l}\text { 4- Utilizar a noção de probabilidade, } \\
\text { combinatória e estatística em } \\
\text { situações - problema. }\end{array}$ \\
\hline
\end{tabular}




\begin{tabular}{|c|c|c|}
\hline $\begin{array}{l}\text { Leitura, interpretação } \\
\text { representação de dados em tabelas } \\
\text { de dupla entrada e gráficos de } \\
\text { barras }\end{array}$ & $\begin{array}{l}\text { (EF03MA26) Resolver problemas } \\
\text { cujos dados estão apresentados em } \\
\text { tabelas de dupla entrada, gráficos } \\
\text { de barras ou de colunas. } \\
\text { (EF03MA27) Ler, interpretar e } \\
\text { comparar dados apresentados } \\
\text { em tabelas de dupla entrada, } \\
\text { gráficos de barras ou de colunas, } \\
\text { envolvendo resultados de pesquisas } \\
\text { significativas, utilizando termos } \\
\text { como maior e menor frequência, } \\
\text { apropriando-se desse tipo de } \\
\text { linguagem para compreender } \\
\text { aspectos da realidade sociocultural } \\
\text { significativos. }\end{array}$ & $\begin{array}{l}\text { 2-Resolver situações-problema com } \\
\text { dados apresentados de maneira } \\
\text { organizada por meio de tabelas e } \\
\text { gráficos. }\end{array}$ \\
\hline $\begin{array}{l}\text { Coleta, classificação } \\
\text { representação de dados referentes } \\
\text { a variáveis categóricas, por meio de } \\
\text { tabelas e gráficos }\end{array}$ & $\begin{array}{l}\text { (EF03MA28) Realizar pesquisa } \\
\text { envolvendo variáveis categóricas } \\
\text { em um universo de até } 50 \\
\text { elementos, organizar os dados } \\
\text { coletados utilizando listas, tabelas } \\
\text { simples ou de dupla entrada e } \\
\text { representá-los em gráficos de } \\
\text { colunas simples, com e sem uso de } \\
\text { tecnologias digitais. }\end{array}$ & $\begin{array}{l}\text { 4- Utilizar a noção de probabilidade, } \\
\text { combinatória e estatística em } \\
\text { situações - problema. }\end{array}$ \\
\hline & & \\
\hline $\begin{array}{l}\text { Análise da ideia de acaso em } \\
\text { situações do } \\
\text { cotidiano: espaço amostral }\end{array}$ & $\begin{array}{l}\text { (EF03MA26) Resolver problemas } \\
\text { cujos dados estão apresentados em } \\
\text { tabelas de dupla entrada, gráficos } \\
\text { de barras ou de colunas. }\end{array}$ & $\begin{array}{l}\text { 4- Utilizar a noção de probabilidade, } \\
\text { combinatória e estatística em } \\
\text { situações - problema. }\end{array}$ \\
\hline $\begin{array}{l}\text { Leitura, interpretação } \\
\text { representação de dados em tabelas } \\
\text { de dupla entrada e gráficos de } \\
\text { barras }\end{array}$ & $\begin{array}{l}\text { (EF03MA27) Ler, interpretar e } \\
\text { comparar dados apresentados } \\
\text { em tabelas de dupla entrada, } \\
\text { gráficos de barras ou de colunas, } \\
\text { envolvendo resultados de pesquisas } \\
\text { significativas, utilizando termos } \\
\text { como maior e menor frequência, } \\
\text { apropriando-se desse tipo de } \\
\text { linguagem para compreender } \\
\text { aspectos da realidade sociocultural } \\
\text { significativos. }\end{array}$ & $\begin{array}{l}\text { 3- Ler informações e dados } \\
\text { apresentados de maneira } \\
\text { organizada por meio de gráficos } \\
\text { (particularmente em gráficos de } \\
\text { colunas). }\end{array}$ \\
\hline $\begin{array}{l}\text { Diferenciação entre variáveis } \\
\text { categóricas e variáveis numéricas. } \\
\text { Coleta, classificação } \\
\text { representação de dados referentes } \\
\text { a variáveis categóricas, por meio de } \\
\text { tabelas e gráficos }\end{array}$ & $\begin{array}{l}\text { (EF03MA28) Realizar pesquisa } \\
\text { envolvendo variáveis categóricas } \\
\text { em um universo de até } 50 \\
\text { elementos, organizar os dados } \\
\text { coletados utilizando listas, tabelas } \\
\text { simples ou de dupla entrada e } \\
\text { representá-los em gráficos de } \\
\text { colunas simples, com e sem uso de } \\
\text { tecnologias digitais. }\end{array}$ & $\begin{array}{l}\text { 1- Elaborar e organizar tabelas } \\
\text { e gráficos, utilizando coletas de } \\
\text { dados em situações do cotidiano, } \\
\text { bem como ler e interpretar suas } \\
\text { informações. }\end{array}$ \\
\hline
\end{tabular}




\begin{tabular}{|c|c|c|}
\hline \multicolumn{2}{|c|}{$5^{\circ}$ ano } & \\
\hline $\begin{array}{l}\text { Espaço amostral: análise de } \\
\text { chances de eventos aleatórios }\end{array}$ & $\begin{array}{l}\text { (EF05MA22) Apresentar todos } \\
\text { os possíveis resultados de um } \\
\text { experimento aleatório, estimando } \\
\text { se esses resultados são igualmente } \\
\text { prováveis ou não. }\end{array}$ & $\begin{array}{l}\text { 4- Utilizar a noção de probabilidade, } \\
\text { combinatória e estatística em } \\
\text { situações - problema. }\end{array}$ \\
\hline $\begin{array}{l}\text { Cálculo de probabilidade de eventos } \\
\text { Equiprováveis }\end{array}$ & $\begin{array}{l}\text { (EF05MA23) Determinar a } \\
\text { probabilidade de ocorrência de um } \\
\text { resultado em eventos aleatórios, } \\
\text { quando todos os resultados } \\
\text { possíveis têm a mesma chance de } \\
\text { ocorrer (equiprováveis). }\end{array}$ & $\begin{array}{l}\text { 4- Utilizar a noção de probabilidade, } \\
\text { combinatória e estatística em } \\
\text { situações - problema. }\end{array}$ \\
\hline $\begin{array}{l}\text { Leitura, coleta, classificação } \\
\text { interpretação e } \\
\text { representação de dados em tabelas } \\
\text { de dupla } \\
\text { entrada, gráfico de colunas } \\
\text { agrupadas, gráficos } \\
\text { pictóricos e gráfico de linhas }\end{array}$ & $\begin{array}{l}\text { (EF05MA24) Interpretar dados } \\
\text { estatísticos apresentados em } \\
\text { textos, tabelas e gráficos (colunas } \\
\text { ou linhas), referentes a outras } \\
\text { áreas do conhecimento ou a outros } \\
\text { contextos, como saúde e trânsito, } \\
\text { e produzir textos com o objetivo de } \\
\text { sintetizar conclusões. } \\
\text { (EF05MA25) Realizar pesquisa } \\
\text { envolvendo variáveiscategóricas } \\
\text { e numéricas, organizar dados } \\
\text { coletados por meio de tabelas, } \\
\text { gráficos de colunas, pictóricos } \\
\text { e de linhas, com e sem uso de } \\
\text { tecnologias digitais, e apresentar } \\
\text { texto escrito sobre a finalidade da } \\
\text { pesquisa e a síntese dos } \\
\text { resultados. }\end{array}$ & $\begin{array}{l}\text { 3- Ler informações e dados } \\
\text { apresentados de maneira } \\
\text { organizada por meio de gráficos } \\
\text { (particularmente em gráficos de } \\
\text { colunas). } \\
\text { 1- Elaborar e organizar tabelas } \\
\text { e gráficos, utilizando coletas de } \\
\text { dados em situações do cotidiano, } \\
\text { bem como ler e interpretar suas } \\
\text { informações. }\end{array}$ \\
\hline
\end{tabular}

Após a construção da tabela fica evidente que os elementos presentes em cada ano não diferem em sua essência, por assim dizer. Entretanto, a Base especifica com mais eficácia a direção em que o docente precisa caminhar assim sendo os saberes acabam se aproximando muito mais dos objetos de conhecimento do que das habilidades. Ainda assim, seria possível ampliá-lo de modo a contemplar objetos de conhecimento e saberes em um único item.

No primeiro ano, por exemplo, vê-se o conteúdo noção de acaso inserido na ideia que o saber apresenta, mas no caso do saber é importante que o professor conheça os contextos a serem trabalhos em combinatória e probabilidade. Já quando lemos a habilidade (EF01MA20) na qual percebe-se as ações a serem realizadas por meio dos verbos que representam as ações a serem realizadas tendo assim as ideias principais a serem trabalhadas descritas minuciosamente.
Examinado os outros anos e habilidades subsequentes observa-se os mesmos pontos descritos acima variando os níveis de complexidade que vão sendo modificadas ao longo de cada para o seu aprofundamento. No saber à medida que se refere à lógica do ciclo, mas, não explicita detalhadamente o que deve realizar ficando a cargo do grupo docente de cada unidade escolar ao realizar seus planejamentos especificar estas ações.

A partir desse ponto, o propósito primeiro deste trabalho se encerra na análise de comparação. Entretanto, surgem outras dúvidas sobre o acompanhamento avaliativo faria alguma diferença? Um docente mais experiente poderia sentir maior liberdade de cátedra com uma orientação mais ampla, aberta? É sempre bom quando um estudo suscita outras questões e desafios a serem refletidos provando que a ideia de inacabamento presente em Paulo Freire é sempre muito real. 


\section{revista educação}

\section{CONSIDERAÇÕES FINAIS}

A reestruturação dos currículos ao redor do Brasil é uma necessidade e uma urgência em nosso país. Para tanto, foi promovida uma comparação entre a Base Nacional Comum Curricular e a Proposta Curricular: Quadro de Saberes Necessários em suas discussões sobre Probabilidade e Estatística /Tratamento da Informação.

A análise não se apresenta com o intuito de concluir e/ou findar as discussões, mas sim de abordar uma possiblidade de ligação e conversa entre saberes e habilidades. Um diálogo entre os currículos formais que podem amparar as discussões em outros níveis curriculares como o interpretado (autores de materiais e outros), da e para a necessidade de tradução desses currículos para os projetos políticos pedagógicos e dos currículos interpretados pelos professores.

Ao comparar quatro saberes e dezessete habilidades, não se percebeu a ausência de objetos de conhecimento da Base no QSN sendo uma possível reestruturação ocorreria no intuito de ampliar ou reorganizar estes saberes clareando ainda mais as ações que devem ser realizadas e aprofundadas em sala de aula.

\section{REFERÊNCIAS}

BRASIL. Ministério da Educação. Secretaria de Educação Básica. Base Nacional Comum Curricular. Brasília: Ministério da Educação, 2017. Disponível em: <http://basenacionalcomum.mec.gov.br/>. Acesso em: 01 fev. 2018.

BRASIL. Ministério da Educação. Secretaria de Educação Básica. Pacto nacional pela alfabetização na idade certa: Educação Estatística. Brasilia: Mec, 2014. 80 p. (Caderno 7).

GUARULHOS. Prefeitura de Guarulhos. Secretaria Municipal de Educação. Proposta Curricular: quadro de saberes necessários. Guarulhos: Secretaria de Educação, 2009. Disponível em: <http:// www.guarulhos.sp.gov.br/pagina/publicações>. Acesso em: 01 fev. 2018.

VASCONCELLOS, Celso dos Santos. Planejamento: projeto de ensino-aprendizagem e projeto político pedagógico. 9. ed. São Paulo: Libertad, 2000. 1 v. 